\title{
Mathematic modeling and cardiac surgery
}

\author{
Michael K. Pasque, MD
}

See related article on page 700 .

From the Division of Cardiothoracic Surgery, Washington University School of Medicine, St Louis, Mo.

Received for publication Aug 31, 2001; accepted for publication Sept 13, 2001.

Address for reprints: Michael K. Pasque, MD, Division of Cardiothoracic Surgery, Washington University School of Medicine, Suite 3103 Queeny Tower, One Barnes-Jewish Hospital Plaza, St Louis, MO 63110 (E-mail: pasquem@msnotes.wustl.edu).

J Thorac Cardiovasc Surg 2002;123:617-20

Copyright (C) 2002 by The American Association for Thoracic Surgery

0022-5223/2002\$35.00+0 $\mathbf{1 2 / 1 / 1 2 0 3 4 0}$

doi:10.1067/mtc. 2002.120340

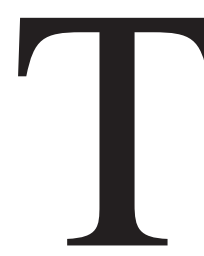

he article by Kramer and colleagues ${ }^{1}$ in this month's issue of the Journal represents yet another effort by an established clinical investigative unit to extend sophisticated mathematic modeling methodology to the clinical setting of cardiac surgery. That these methods can be readily applied in this setting is well demonstrated by this investigation, as well as by others. ${ }^{2-7}$ What may be less apparent is the potential full impact of this technology on the day-to-day clinical practice of cardiac surgery.

By way of illustration, it was not readily accepted, until the application of mathematic modeling theory, that systolic function in patients with dilated left ventricles could be improved by means of surgical or medical interventions to effect isolated left ventricular (LV) volume reduction. The degree to which preload and afterload are inherently, unquestionably, and irrevocably tied together and, indeed, overlap has only been brought to the forefront by the application of these principles that examine ventricular systolic performance at the level of its very basic building blocks: stress and strain. The fact that a markedly dilated end-diastolic ventricular dimension results in elevated end-diastolic, and therefore elevated early systolic, ventricular wall stress was tacitly understood by mechanics investigators. That this increase in early systolic stress, however, was the equivalent of what we clinically refer to as increased afterload was not readily apparent until its clarification by means of mathematic modeling. In other words, the ventricular volume reduction that one might obtain, for instance, by eliminating severe mitral regurgitation has the ability to reduce early systolic wall stress and therefore to reduce afterload during systolic ejection.

Unfortunately, old paradigms fall hard. The appreciation that an improvement in LV ejection fraction can be expected after mitral valve repair for severe mitral regurgitation because of a reduction in afterload is still not readily accepted. Instead, surgeons still cling to the old paradigm. They fear that the repair of mitral regurgitation results in an immediate increase in afterload during systolic ejection and therefore an immediate reduction in LV ejection fraction. The old paradigm completely ignores the importance of ventricular dimension on systolic afterload. Clinging to these old wives' tales unfortunately allows us to avoid the reality that poor outcomes after intervention in the setting of mitral regurgitation are most likely the result of other factors, such as poor myocardial protection. Obviously, the repercussions of the introduction of mathematic modeling to the clinical setting can be far reaching and have the potential to profoundly affect the clinical practice of cardiac surgery.

Kramer and colleagues ${ }^{1}$ have given the reader compelling evidence that the application of these techniques in the clinical setting of surgical intervention for LV aneurysm may, in a similar fashion, have the ability to reform our thinking in this area. Once again, the consequences of changing thought in this area are far reaching in the era of surgical ventricular remodeling, as we attempt to apply new reconstructive techniques in routine LV aneurysmectomy, as well as in surgical intervention for akinetic regions ${ }^{8-10}$ or for anterior myocardial infarction. ${ }^{11}$ The stage is 
set because these modeling methods have demonstrated the capacity to define how the heart responds to various clinically relevant insults, including acute myocardial infarction, ${ }^{3}$ pulmonary hypertension, ${ }^{6}$ and valvular regurgitation. ${ }^{7}$ The pathologic remodeling processes that can occur in these settings deserve diligent study in the hopes of teasing out the factors that influence the ultimate natural course of the disease and therefore best define appropriate intervention points. Perhaps more important, however, the reverse remodeling processes that may or may not occur after medical or surgical intervention in dilated cardiomyopathy, ${ }^{2}$ valvular regurgitation, acute myocardial infarction, pulmonary hypertension, ${ }^{6}$ or LV aneurysm deserve close scrutiny with the ever more sophisticated modeling tools that have recently become available.

The authors take a very important step in this regard when they attempt to characterize the reverse remodeling process in a small group of patients who have undergone surgical intervention for LV aneurysm. More studies in larger groups of patients are needed as the mythology surrounding LV aneurysmectomy is cautiously reassessed. Specifically, we hope to see the age-old fear involving inadequate residual LV volume analyzed in a critical and quantitative fashion. It has long been suspected by mechanics investigators that more harm may be done than avoided by surgeons who leave behind akinetic or even dyskinetic LV wall segments because the closure or patch reconstruction is altered to allow for a larger residual volume than is necessary.

In addition, mathematic modeling theory was the impetus for, and a strong substantiation of, the recent emphasis on the geometric considerations in reconstructive techniques. ${ }^{12,13}$ Attention to such qualities as sphericity and symmetry and on returning the ventricle as closely as possible to its original shape becomes a logical and accessible goal once the relative importance of various geometric parameters are determined by means of mathematic modeling. Certainly, if there is anything that these techniques have taught us, it is that fully 3-dimensional geometry is of critical importance in determining both regional and global ventricular wall mechanics. Appropriate geometry after reconstruction can be the difference between success and failure because of its direct and sometimes profound influence on stress and strain and, therefore, resulting systolic and diastolic function.

The current work by Kramer and colleagues also supports the notion that mathematical modeling may have the potential to redefine the border zones surrounding LV scars, specifically in regard to their ultimate ability to contribute to the systolic function of the heart. ${ }^{14}$ Surgeons should not fear altering patch closure to protect fragile border zones. The difference in outcome may be profound because one reconstruction may allow border zone contribution to late systolic ejection, ${ }^{15}$ whereas a lesser reconstructive technique may relegate that border zone to subsequent remodeling that renders it a completely nonfunctional region.

In addition, the authors have once again addressed the importance of the influence of the aneurysm reconstruction on the remaining, remote, normal ventricular wall regions. Their data appear to confirm previous information ${ }^{16}$ suggesting that the systolic contraction of these remote walls is improved postoperatively. The responsible mechanism is similar to that described above for patients with mitral regurgitation and is, in fact, a common thread that runs through almost all surgical interventions for dilated cardiomyopathy of any etiology. Again, mathematic modeling predicts that the reduction in end-diastolic, and therefore early systolic, wall stress by contractile chamber volume reduction results in a reduction of afterload and therefore improved regional systolic performance in the remote normal wall segments. These studies add to the growing clinical experience with surgical LV reconstructive procedures in a wide spectrum of regional pathologic conditions that suggest that ventricular volume reduction with geometrically appropriate 3-dimensional reconstruction techniques may have a strong role in improving outcomes in these difficult patient subsets.

How do we go about making these sophisticated clinical assessments? First, we need to determine what the output from our work should be. What new clinically relevant information can these methods be expected to supply? As mentioned, these advanced techniques primarily deal with myocardial wall stress and strain, the most fundamental units of myocardial function. Stress is most simply defined as force distributed over area of myocardium and strain as a normalized measure of relative myocardial point displacement. Increases in LV wall stress have a direct and often profound effect on the molecular biology of the involved myocardium, including the stimulation of compensatory mechanisms that, although based at the subcellular level, have effects measurable at the macroscopic level. ${ }^{17}$ Systolic strain measurement, on the other hand, has the ability to quantify systolic performance at a near cellular level. Regional wall stress and strain will, almost assuredly, be the measurable parameters that correlate best with the molecular changes that seem to be controlling the development of myocardial dysfunction. ${ }^{17}$ In many cases they may be the forces that are driving the cellular molecular biology that determines the progression of, or recovery from, clinical heart failure.

Basic input is needed to make these determinations of myocardial wall stress and strain. This input is usually composed of measurements of intracavitary LV pressure and 3-dimensional LV wall geometry and displacements examined within the framework of myocardial material properties and constraints. LV pressure measurement is 
relatively straightforward. Even peripheral measurement of blood pressure can suffice when assessing systole because the open aortic valve allows for a reasonable peripheral reflection of intracavitary pressure. Accurate assessment of LV wall 3-dimensional geometry and point displacements is, however, another issue altogether. Just like any mathematical system, the quality of the output is directly dependent on the quality of the input data. This is where the recent improvements in the assessment of these geometric parameters with magnetic resonance imaging (MRI) enter the picture. Previous clinical applications of stress/strain indices used the tools that were available at that time to supply input data. These included ejection fraction assessed by means of left ventriculography and echocardiography, wall thickening assessed by means of echocardiography, and occasionally radionuclide left ventriculography. The limited nature of these crude global measurements of LV wall displacement mandated expansive assumptions (of prolate spheroidal LV geometry, for instance) in the application of mathematical modeling. In addition, the global nature of most of these measurement tools limited their capability to accurately and quantitatively assess regional, let alone transmural, changes.

The introduction of MRI and radiofrequency tissue tagging changed all of that. Radiofrequency tissue tagging allows the permeation of 3-dimensional crosshatch grids throughout the LV myocardium. The grid intersection points can then be tracked throughout the cardiac cycle by means of rapid magnetic resonance scanning. For the first time, this has allowed clinical investigators to accurately determine transmural, regional 3-dimensional myocardial point displacements. From these point displacements, regional 3-dimensional myocardial strain can be determined. From these strain determinations, highly accurate 3-dimensional strain maps of the LV myocardial wall can be generated by means of standard interpolation and fitting algorithms. These strain maps represent the most sophisticated and highly quantified assessment of global, regional, and transmural ventricular wall function that has ever been made available to clinical investigators. Their introduction has opened a big hole in a formidable defensive line and made possible a little open-field running for mechanics investigators like Kramer and colleagues.

Mathematical modeling of the heart is here to stay. Its clinical use has repeatedly demonstrated that, in regard to myocardial mechanics and heart surgery, what we knew for sure is simply not for sure. As the sophisticated mathematical modeling systems that have been developed for application in other engineering venues continue to be incorporated into computer-based, semiautomated, clinically applicable algorithms that minimize examiner effort and bias, an incredibly powerful clinical investigative tool for the study of myocardial mechanics is emerging. These sys- tems, combined with the improvements in patient-specific, fully 3-dimensional geometric data input that are afforded by MRI with radiofrequency tissue tagging, may herald the ultimate cardiac diagnostic tool of the future. As rapid imaging in open magnetic resonance scanners becomes widespread and the coronary anatomic imaging capabilities of MRI improve, one can, without much difficulty, envision the one-stop testing of patients with almost any suspected cardiac disease. The key to the ultimate success of these methodologies, however, is in the sometimes daring and always arduous first steps of the clinical investigators, such as Kramer and colleagues, who have developed the clinical methods to bring the mathematics to the bedside. Even those of us with somewhat limited vision can readily see that we are on the verge of a very exciting time in the extension of these techniques to the patient with cardiovascular disease.

\section{References}

1. Kramer CM, Magovern JA, Rogers WJ, Vido D, Savage EB. Reverse remodeling and improved regional function after repair of left ventricular aneurysm. J Thorac Cardiovasc Surg. 2002;123:700-6.

2. Bogaert J, Rademakers FE. Regional nonuniformity of normal adult human left ventricle. Am J Physiol Heart Circ Physiol. 2001;280: H610-20.

3. Bogaert J, Bosmans H, Maes A, Suetens P, Marchal G, Rademakers FE. Remote myocardial dysfunction after acute anterior myocardial infarction: impact of left ventricular shape on regional function: a magnetic resonance myocardial tagging study. J Am Coll Cardiol. 2000;35:1525-34.

4. Young AA, Dokos S, Powell KA, Sturm B, McCulloch AD, Starling $\mathrm{RC}$, et al. Regional heterogeneity of function in nonischemic dilated cardiomyopathy. Cardiovasc Res. 2001;49:308-18.

5. Moore CC, Lugo-Olivieri CH, McVeigh ER, Zerhouni EA. Threedimensional systolic strain patterns in the normal human left ventricle: characterization with tagged MR imaging. Radiology. 2000;214:45366.

6. Moulton MJ, Creswell LL, Ungacta FF, Downing SW, Szabo BA, Pasque MK. Magnetic resonance imaging provides evidence for remodeling of the right ventricle after single-lung transplantation for pulmonary hypertension. Circulation. 1996;94:(Suppl)II-312-9.

7. Ungacta FF, Davila-Roman VG, Moulton MJ, Cupps BP, Moustakidis $\mathrm{P}$, Fishman DS, et al. MRI-radiofrequency tissue tagging in patients with aortic insufficiency before and after operation. Ann Thorac Surg. 1998;65:943-50.

8. Di Donato M, Sabatier M, Montiglio F, Maioli M, Toso A, Fantini F, et al. Outcome of left ventricular aneurysmectomy with patch repair in patients with severely depressed pump function. Am J Cardiol. 1995; 76:557-61.

9. Dor V. Left ventricular aneurysms: the endoventricular circular patch plasty. Semin Thorac Cardiovasc Surg. 1997;9:123-30.

10. Di Donato M, Sabatier M, Dor V, Toso A, Maioli M, Fantini F. Akinetic versus dyskinetic postinfarction scar: relation to surgical outcome in patients undergoing endoventricular circular patch plasty repair. J Am Coll Cardiol. 1997;29:1569-75.

11. Athanasuleas CL, Stanley AW Jr, Buckberg GD, Dor V, Di Donato M, Blackstone EH. Surgical anterior ventricular endocardial restoration (SAVER) in the dilated remodeled ventricle after anterior myocardial infarction. RESTORE group. Reconstructive Endoventricular Surgery, returning Torsion Original Radius Elliptical Shape to the LV. J Am Coll Cardiol. 2001;37:1199-209.

12. Dor V, Montiglio F, Sabatier M, Coste P, Barletta G, Di Donato M, et al. Left ventricular shape changes induced by aneurysmectomy with endoventricular circular patch plasty reconstruction. Eur Heart J. 1994;15:1063-9. 
13. Di Donato M, Sabatier M, Dor V, Gensini GF, Toso A, Maioli M, et al. Effects of the Dor procedure on left ventricular dimension and shape and geometric correlates of mitral regurgitation one year after surgery. J Thorac Cardiovasc Surg. 2001;121:91-6.

14. Moulton MJ, Downing SW, Creswell LL, Fishman DS, Amsterdam DM, Szabo BA, et al. Mechanical dysfunction in the border zone of an ovine model of left ventricular aneurysm. Ann Thorac Surg. 1995;60: 986-98.

15. Dor V, Sabatier M, Di Donato M, Montiglio F, Toso A, Maioli M. Efficacy of endoventricular patch plasty in large postinfarction aki- netic scar and severe left ventricular dysfunction: comparison with a series of large dyskinetic scars. J Thorac Cardiovasc Surg. 1998;116: 50-9.

16. Di Donato M, Sabatier M, Toso A, Barletta G, Baroni M, Dor V, et al. Regional myocardial performance of non-ischaemic zones remote from anterior wall left ventricular aneurysm: effects of aneurysmectomy. Eur Heart J. 1995;16:1285-92.

17. St John Sutton MG, Sharpe N. Left ventricular remodeling after myocardial infarction: pathophysiology and therapy. Circulation. 2000;101:2981-8

Access to The Journal of Thoracic and Cardiovascular Surgery Online is reserved for print subscribers!

Full-text access to The Journal of Thoracic and Cardiovascular Surgery Online is available for all print subscribers. To activate your individual online subscription, please visit The Journal of Thoracic and Cardiovascular Surgery Online, point your browser to http://www.mosby.com/jtcvs, follow the prompts to activate your online access, and follow the instructions. To activate your account, you will need your subscriber account number, which you can find on your mailing label (note: the number of digits in your subscriber account number varies from 6 to 10). See the example below in which the subscriber account number has been circled:

\section{Sample mailing label}

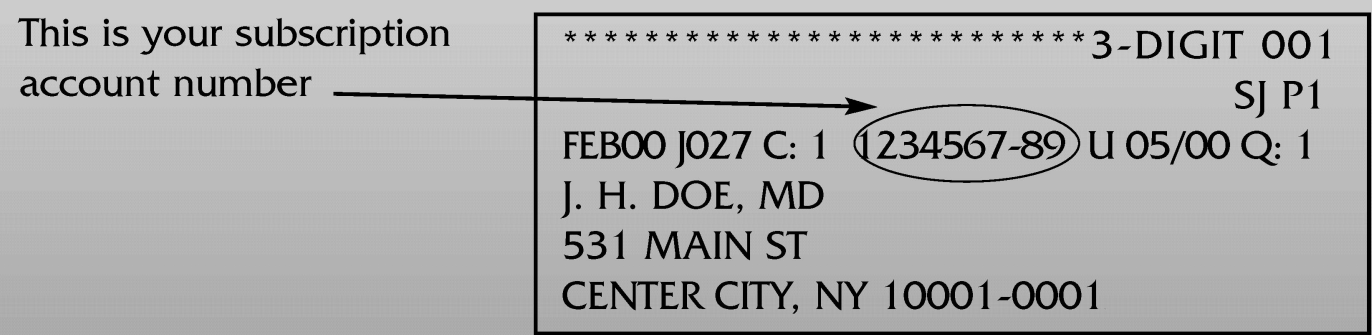

Personal subscriptions to The Journal of Thoracic and Cardiovascular Surgery Online are for individual use only and may not be transferred. Use of The Journal of Thoracic and Cardiovascular Surgery Online is subject to agreement to the terms and conditions as indicated online. 